\title{
Intraductal cholangioscopy for the diagnosis of pancreaticobiliary maljunction
}

An 8-year-old girl was admitted to our department because of acute pancreatitis. She had undergone laparoscopic cholecystectomy 2 weeks previously. A 13-mm dilatation of the common bile duct (CBD) and a biliary tract obstruction next to the papilla were observed on magnetic resonance imaging (MRI) during hospitalization ( $\triangleright$ Fig. 1). After endoscopic sphincterotomy was carried out during endoscopic retrograde cholangiopancreatography (ERCP), proteinaceous material was removed from the distal end of the bile duct ( $>$ Fig. 2), with resolution of the biliary obstruction. When radiographic contrast dye was injected into the distal bile duct, the pancreatic duct, a dilated CBD similar to a choledochal cyst, and a long common channel were observed ( $\mathbf{F i g . 3}$ ). Therefore, a pancreaticobiliary maljunction (PBM) was suspected. Subsequently, an intraductal cholangioscopy using the SpyGlass DS Direct Visualization System (Boston Scientific Co., Natick, Massachusetts, USA) was performed to confirm a PBM type I, in which the pancreatic duct enters the CBD ( $\mathbf{F i g . 4 ; ~ V i d e o ~ 1 ) . ~}$

$\mathrm{PBM}$ is a congenital anomaly in which the pancreatic and bile ducts are joined outside the duodenal wall, usually forming a long common channel [1]. There are two modes of junction: type I (pancreaticobiliary type) and type II (biliary-pancreatic type) [2]. The incidence is $4.1 \%$ [3] and it may or may not be associated with biliary dilatation (i.e. congenital choledochal cyst). Because of the PBM, the junction is not directly affected by the sphincter of Oddi; therefore, continuous reflux between the pancreatic and biliary juices occurs, which results in protein plugs. Different pathological conditions have been associated, such as acute pancreatitis, gallstones, and biliary cancer (gallbladder and bile duct) [4]. PBM can

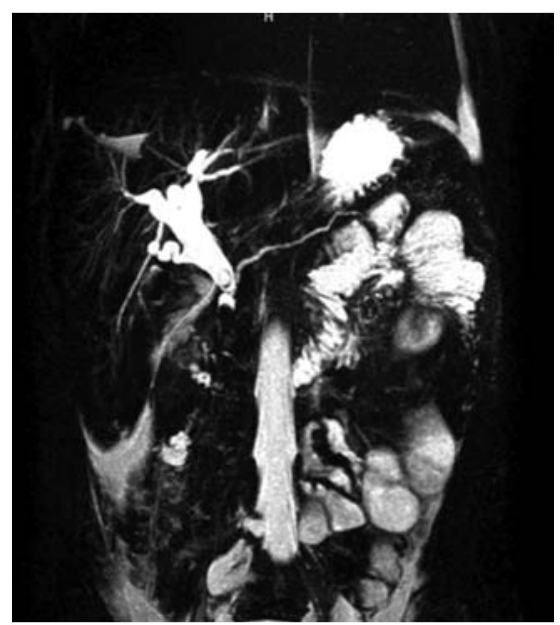

- Fig. 1 Magnetic resonance imaging showing a $13-\mathrm{mm}$ dilatation of the common bile duct and a biliary tract obstruction at the end of the common bile duct.

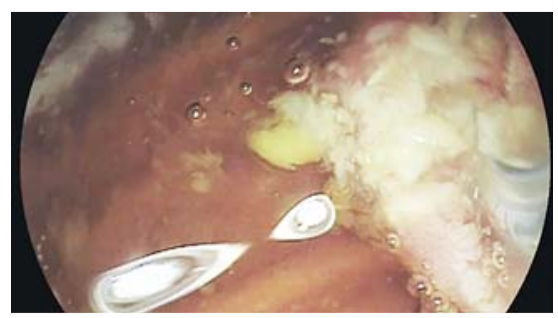

> Fig. 2 Image during endoscopic retrograde cholangiopancreatography showing a protein plug compacted in the common bile duct visible through the papilla following endoscopic sphincterotomy.

be diagnosed either by imaging tests (ERCP, percutaneous transhepatic cholangiography, MRI) or surgical examination [5].

We showed that intraductal cholangioscopy using the SpyGlass DS System can be a novel diagnostic tool that allows direct visualization of a PBM.

Endoscopy_UCTN_Code_TTT_1AR_2AK

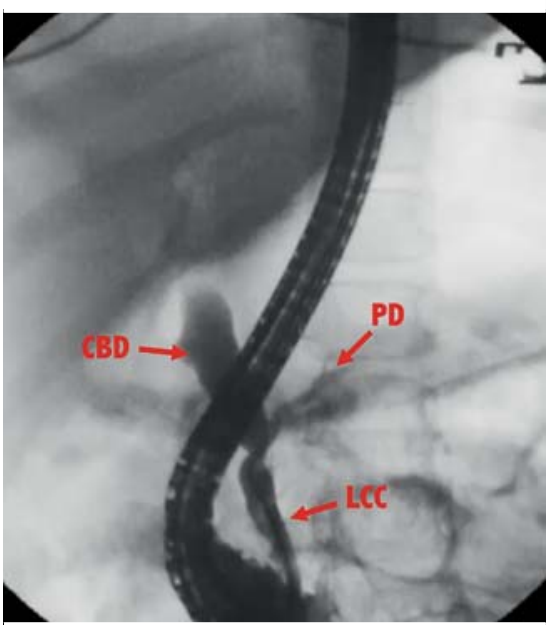

- Fig. 3 Radiographic image during endoscopic retrograde cholangiopancreatography showing pancreaticobiliary maljunction. CBD, common bile duct; $\mathrm{PD}$, pancreatic duct; LCC, long common channel.

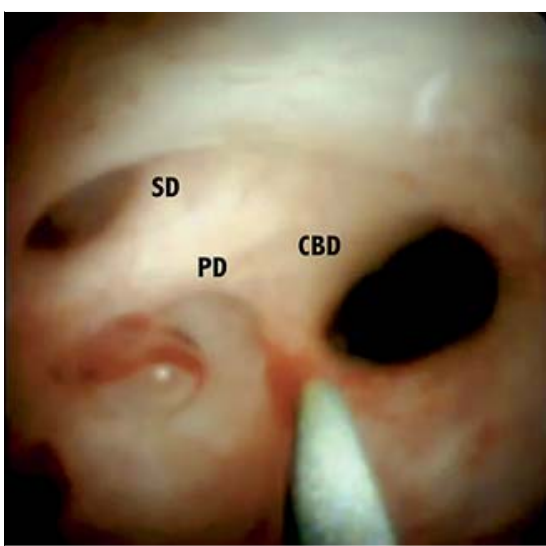

- Fig.4 Image during intraductal cholangioscopy (SpyGlass DS system) showing direct visualization of a pancreaticobiliary maljunction. CBD, common bile duct; PD, pancreatic duct; SD, Santorini duct.

\section{Competing interests}

Dr. Aparicio is consultant for Boston Scientific. The other authors have nothing to disclose. 


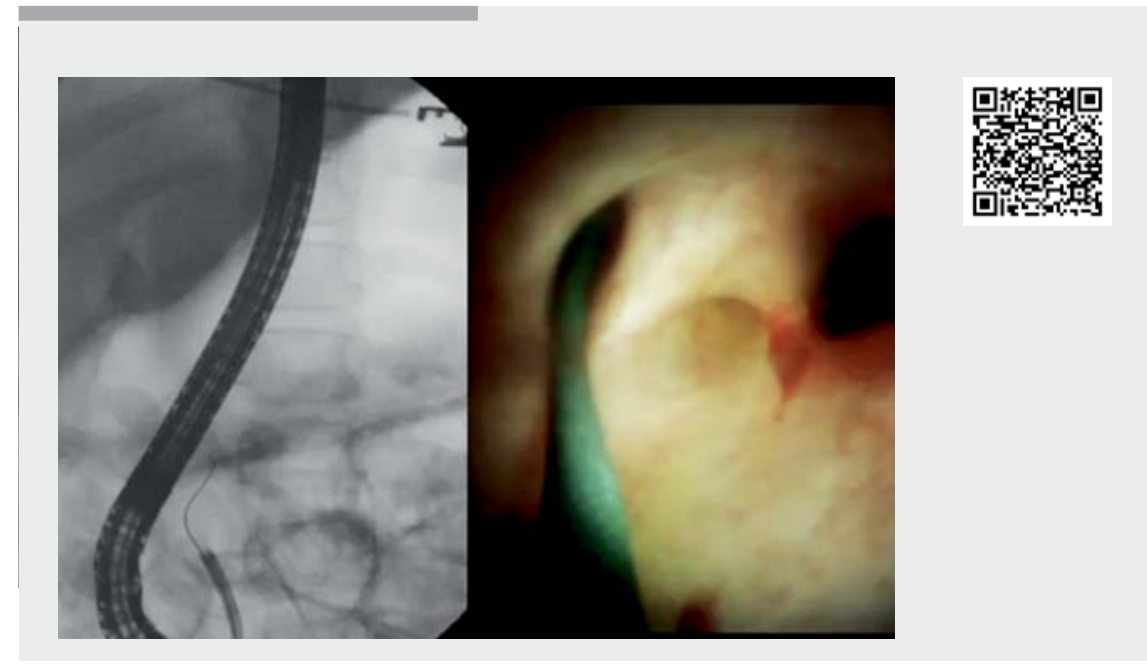

$\checkmark$ Video 1 Intraductal cholangioscopy (SpyGlass DS system) showing direct visualization of a pancreaticobiliary maljunction. Guidewire advancement under fluoroscopic guidance allowed each duct to be identified.

The authors

\section{Carolina Mangas-Sanjuan, Maryana Bozhychko, Luis Compañy, Francisco Ruiz, Juan Martinez, Juan Antonio Casellas, José Ramón Aparicio}

Endoscopy Unit, Hospital General Universitario de Alicante, Instituto de Investigación Sanitaria y Biomédica de Alicante, ISABIAL, Alicante, Spain

\section{Corresponding author}

\section{José Ramón Aparicio, MD}

Endoscopy Unit, Hospital General

Universitario de Alicante, C/ Pintor Baeza 12,

03010 Alicante, Spain

japariciot@gmail.com

\section{References}

[1] Kamisawa T, Kaneko K, Itoi T et al. Pancreaticobiliary maljunction and congenital biliary dilatation. Lancet Gastroenterol Hepatol 2017; 2: 610-618

[2] Kimura K, Ohto M, Ono T. Congenital cystic dilatation of the common bile duct; relationship to anomalous pancreaticobiliary ductal union. AJR Am J Roentgenol 1977; 128: $571-577$

[3] Kim H], Kim MH, Lee SK et al. Normal structure, variations, and anomalies of the pancreaticobiliary ducts of Koreans: a nationwide cooperative prospective study. Gastrointest Endosc 2002; 55: 889-896

[4] Morine Y, Shimada M, Takamatsu $\mathrm{H}$ et al. Clinical features of pancreaticobiliary maljunction: update analysis of 2nd Japannationwide survey. J Hepatobiliary Pancreat Sci 2013; 20: $472-480$

[5] Kamisawa T, Ando H, Hamada Y et al. Diagnostic criteria for pancreaticobiliary maljunction 2013. J Hepatobiliary Pancreat Sci 2014; 21: 159-161

\section{Bibliography}

DOI https://doi.org/10.1055/a-0977-2583

Published online: 9.8.2019

Endoscopy 2020; 52: E9-E10

(c) Georg Thieme Verlag KG

Stuttgart · New York

ISSN 0013-726X

\section{ENDOSCOPY E-VIDEOS}

https://eref.thieme.de/e-videos

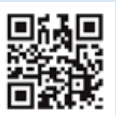

Endoscopy E-Videos is a free access online section, reporting on interesting cases and new techniques in gastroenterological endoscopy. All papers include a high quality video and all contributions are freely accessible online.

This section has its own submission website at https://mc.manuscriptcentral.com/e-videos 